\title{
Editor's Introduction: Pediatric Epilepsy and Epilepsy Surgery
}

\author{
Gary W. Mathern, Los Angeles, Calif., USA
}

Seizures are a frequent occurrence in infancy and childhood. Although $70-75 \%$ of patients can be controlled with antiepileptic drugs, refractory cases are common and the resulting seizures customarily severe. Many of these severe and refractory cases have pathologic substrates, such as cortical dysplasia (CD) or Rasmussen's encephalitis, and these patients are possible surgical candidates. Seizure control in young children, whether from pharmacologic or surgical treatment, is desirable for it should prevent the possible epilepsy-associated cognition, language and development problems and reduce the psychosocial impact of epilepsy in school age children. Despite these important potential clinical advantages, early surgery in children with refractory symptomatic epilepsy has been slow to develop as routine medical practice. The reasons commonly cited include that: (1) the natural history of symptomatic epilepsy syndromes has, until recently, not been known precisely (i.e. the seizures may stop spontaneously); (2) neuroimaging had difficulty identifying which patients had lesions, and (3) there was concern that 'generalized' seizures represented diffuse bilateral brain abnormalities or damage despite focal pathologies. In additition, safe surgical risk-to-benefit ratios required an assembly of a team of pediatric neurologists, neurosurgeons, anesthesia and intensive care personnel who work together with the children and their families through the difficult pre- and postsurgical process. Despite these problems over the past 10 years a number of specialized pediatric epilepsy surgery centers have devel-

\begin{tabular}{ll}
\hline KARGER & ( 1999 S. Karger AG, Basel \\
Fax +4161306 1234 & 0378-5866/99/0215-0163\$17.50/0 \\
$\begin{array}{l}\text { E-Mail karger@karger.ch } \\
\text { www.karger.com }\end{array}$ & $\begin{array}{l}\text { Accessible online at: } \\
\text { www.karger.com/journals/dne }\end{array}$
\end{tabular}

oped around the world, and the number of children receiving surgical treatment of their seizures has substantially grown. Put another way, pediatric epilepsy surgery has started to 'mature' as a medical discipline. With more clinical experience it is becoming apparent that early aggressive surgery can control seizures from symptomatic substrates in young children with disease resembling generalized epilepsy.

As is true with any specialized field of neuroscience, increased clinical activity may drive related clinical and basic science questions. For pediatric epilepsy surgery the primary clinical questions have centered around whether seizures have adverse affects on the developing brain that justify the surgical risks, and how surgery and/or seizure control affects postsurgery cerebral development. In addition, surgical removal of the epileptic substrates provides a unique opportunity to examine this tissue to determine what 'lesions' are epileptic, and how that tissue might generate seizures. These clinical-pathologic studies cannot be performed in animals for, so far, substrates like CD and Rasmussen's encephalitis, have not been modeled completely in animals. The basic scientist is also extremely important in the study of pediatric epilepsy and epilepsy surgery for only in animals can we discern changes in electrophysiological and anatomical parameters and find out what features are related to normal cerebral development and what are pathologic and epileptogenic. Relevant questions for the basic researcher include: (1) do large dysmorphic CD cells show anatomic or physiologic fea-

Gary W. Mathern, MD

Division of Neurosurgery, Reed Neurological Research Center

UCLA Medical Center

Los Angeles, CA 90095-1769 (USA)

Tel. +1 310206 8777, Fax +1 310206 8461, E-Mail gmathern@ucla.edu 
tures of 'immature' or 'mature' neurons? (2) do antiepileptic drugs function differently in the young compared to the adult brain? (3) what are the connections, both normal and abnormal, between symptomatic substrates and other cortical structures, and does this explain seizure generation? (4) how does the ketogenic diet or vagal nerve stimulation work? These are just a few of the important questions that will require coordinated efforts of clinical investigators and basic scientists in order to understand these diseases and care for these children with epilepsy.

This special issue of Developmental Neuroscience contains a set of papers on clinical and basic science issues related to pediatric epilepsy and epilepsy surgery. The reason for combining, under one cover, papers that are clini- cal and/or research oriented is based on the editor's bias that as medical investigators it is only by the exchange of information, from the laboratory bench to the operating room and hospital ward, that will lead to better ways of understanding the disease process and ways to correctly treat it. It is hoped that this issue is the start of similar venues in the years to come. As editor of this special issue, I would like to thank all contributors for their excellent efforts and contributions. As readers it is our hope that you find the diverse nature of the topics to be intellectually stimulating and a valuable reference in the field. Additional thanks go to Editor-in-Chief A.T. Campagnoni and Karger for the opportunity to publish this issue. 